\title{
Jurnal
}

\section{FUNCTIONAL ANALYSIS OF THE PERSICARIA MINOR SESQUITERPENE SYNTHASE GENE PROMOTER IN TRANSGENIC ARABIDOPSIS THALIANA}

\author{
Aimi Farehah Omara, Ismanizan Ismaila,b*
}

aCenter of Biotechnology and Functional Foods, Faculty Science and Technology, UKM, 43600, Bangi, Selangor, Malaysia bInstitute of Systems Biology, UKM, 43600, Bangi, Selangor, Malaysia
Article history

Received

29 September 2018

Received in revised form

16 April 2019

Accepted

22 April 2019

Published online

25 June 2019

*Corresponding author maniz@ukm.edu.my

\begin{abstract}
Sesquiterpene synthase is an enzyme involved in sesquiterpene biosynthesis which catalyzed sesquiterpene formation from farnesyl diphosphate (FDP). In this research, the sesquiterpene synthase promoter (PmSS) was isolated from Persicaria minor (P.minor) to identify the functional region of the promoter and possible cis - regulatory element involved in the regulation of sesquiterpene synthase gene. Various putative cis - regulatory element involved in environmental stress and hormones were identified on PmSS promoter. The PmSS promoter and three series of deletion promoter were fused to $\beta$-glucuronidase (gus) gene and transformed into Arabidopsis thaliana. This study showed PmSS promoter was regulated in a developmental specific manner and response to wounding, drought, heat, abscisic acid (ABA) and methyl jasmonate (Me Ja) treatment. The results revealed the existence of cis regulatory elements that control the regulation of promoter activity in a developmental specific manner at -1758 to -1078 promoter sequences. The presence of cis-element acting as a repressor is expected to be present at the promoter between -1540 to $-1078 \mathrm{bp}$. The region from -1078 to -855 was critical for maximal PmSS promoter activity. Deletion of promoter region from -1758 to -855 induced regulation of promoter in an organ-specific manner. Drought stress treatment did not induced GUS activity in deleted ABRE motif construct, suggested that ABRE motif is essential cis element during drought stress.
\end{abstract}

Keywords: Promoter, PmSS, cis-regulatory element, $\beta$-glucuronidase, GUS activity

\begin{abstract}
Abstrak
Sesquiterpene sintase merupakan enzim yang terlibat biosintesis sesquiterpene di mana ia memangkinkan pembentukan sesquiterpene dari farnesil difosfat (FDP). Dalam kajian ini, promoter sesquiterpene sintase (PmSS) dipencilkan dari Persicaria minor (P.minor) untuk mengenal pasti bahagian promoter yang berfungsi dan elemen tindakan cis yang mungkin terlibat dalam pengawalaturan gen sesquiterpene sintase. Pelbagai elemen pengawalaturan cis putatif yang terlibat dalam tekanan persekitaran dan hormone dikenal pasti. Promoter PmSS serta tiga siri delesi promoter digabungkan dengan gen $\beta$ glucuronidase (gus) dan ditransformasikan ke dalam Arabidopsis thaliana. Kajian ini menunjukkan promoter PmSS dikawal atur mengikut tahap perkembangan dan bertindak balas terhadap rawatan tekanan perlukaan, kemarau, haba, asid absisik (ABA) dan metil jasmonat (Me Ja). Hasil kajian mendedahkan kewujudan elemen pengawalaturan cis yang mengawal aktiviti promoter mengikut tahap perkembangan pada jujukan promoter di kedudukan -1758 ke-1078. Kehadiran elemen cis yang bertindak sebagai penindas dijangkakan hadir pada jujukan promoter di antara -1540 ke -1078 pb. Kawasan jujukan -1078 ke-855 adalah penting untuk aktiviti PmSS promoter yang maksimum. Delesi kawasan promoter dari jujukan -1758 ke -855 mengaruh pengawalaturan promoter secara spesifik organ. Rawatan tekanan kemarau tidak mengaruh aktiviti GUS dalam konstruk delesi motif ABRE, bermakna motif ABRE merupakan elemen cis penting semasa tekanan kemarau.
\end{abstract}

Kata kunci: Promoter, PmSS, elemen pengawalaturan cis, $\beta$-glucuronidase, aktiviti GUS

(c) 2019 Penerbit UTM Press. All rights reserved 


\subsection{INTRODUCTION}

Plants are sessile organisms which produce a variety of secondary metabolites as their mechanism in response to environmental stress. The secondary metabolite that is produce by plants are consist of terpenoids, amino acid, fatty acid derivatives and phenylpropanoid (1).Terpenes are the largest class of secondary metabolite most commonly found in plants and act as a defense mechanism from various biotic and abiotic stress. Volatile terpenoid emitted from plants plays an important roles in plants defense, attractant for pollinator and interaction with surrounding environment [2]. Terpene comprised of isoprene molecules [3] and classified into five class based on the number of isoprene unit present in their basic skeleton such as monoterpene, sesquiterpene, diterpene, triterpene dan polyterpene [4].

Sesquiterpenes are C 15 terpenoid made up from three isoprene units and generally found in higher plants,marine organisms and fungi [5]. Sesquiterpene is a volatile compound and is known to contribute to the production of aromatic essential oils [6]. Due to its unique nature, essential oils from sesquiterpene are often used in the production of food, beverages, medicines and cosmetics[ 7]. Sesquiterpene also plays a vital role in direct and indirect plant defense systems such as protection against herbivorous attacks, thus generating chemical signals interactions between plants and insects [8]. In some wild relatives maize species, sesquiterpenes were emitted when attacked by herbivore [9]. Besides that, sesquiterpene (E)- $\beta$-caryophyllene was emitted by Z. mays roots as a response to lepidopteran larva attacks indirectly attracts their natural enemies [10]. Sesquiterpene (E)$\beta$-caryophyllene is also functioning as a defense against a bacterial pathogen, the bacterial growth on the stigma of flower lacking (E)- $\beta$-caryophyllene emission were greater than wildtype flower [11]. Recent studies have found that sesquiterpene acts as a chemo-preventing agent in colon and skin cancer [12]. Because of its commercial value and its vital role in plant defense systems, various studies have been conducted in studying the mechanism of sesquiterpene biosynthesis.

Sesquiterpene was synthesized in two distinct pathways including cytosolic mevalonic-acid (MVA) pathway and deoxyxylulose phosphate (1-deoxy-Dxylulose5-phosphate) pathway [13]. The major step in sesquiterpene biosynthesis involves a group of enzymes known as sesquiterpene synthase. Sesquiterpene synthase is a group of proteins that converts farnesil diphosphate (FPP) to over 300 sesquiterpenes [12]. Since sesquiterpene synthase is directly involved in sesquiterpene production, it is one of the critical vital enzymes that need to be studied extensively. Research at the molecular level is crucial for better understanding of biosynthesis sesquiterpene pathways in plants. For instance studies of promoter improved fundamental knowledge of gene regulation, since its control the regulation of gene expression at the transcriptional level [14]. Expression of the gene during developmental stages, in different tissues or in response to environmental stress-mediated at the transcriptional level. Promoters and their cis-acting elements control the transcriptional regulation which is critical for activation and suppression of gene expression [15]. Hence, the promoters studies are crucial because they are basic to understanding the regulation of gene expression in plants.

To date, sesquiterpene synthase promoter has been studied in various plants species. In Elaies oleifera, the activity of sesquiterpene synthase promoter was induced by exogenous elicitation of Jasmonic acid (JA) [16]. Whereas, in Artemisia annua, the four sesquiterpene synthases $\beta$ caryophyllene (CPS), $\beta$-farnesene (FS), epi-cedrol (ECS), and amorpha-4,11-diene synthase (ADS) promoter were activated by wounding and methyl jasmonate treatment in a time-dependent manner [17]. However, there are limited studies of Sesquiterpene synthase promoter in response to various environmental stress based on cis-acting elements present on the promoter.

Previous studies have proven that abundance of terpenoids particularly sesquiterpenes were found in the essential oils of P.minor, suggesting P.minor as a good source for sesquiterpenes study [18]. P.minor usually known as kesum in Malaysia is an aromatic herbaceous plant that contains high secondary metabolic compounds [19] Hence,widely used as a flavouring agent, food additive and to treat body and stomach aches [20]. In P.minor, a cDNA sequence of (PmSS) gene was successfully cloned and characterized. Prior research has shown that under normal condition the expression of PmSS was regulated differently in different organs and was regulated by the jasmonic acid signalling pathway [21]. Thus, this research aimed to elucidate the functional region of the Pmss promoter and essential cis element that involved in regulation of sesquiterpene synthase gene expression. In the recent study the PmSS gene promoter was isolated and analyzed by PLACE and PLANTCARE database. A series of promoter deletion was created to identify the functional region of Pmss promoter. Later, PmSS promoter and its three deletion version were combined to the GUS gene and transformed into A.thaliana. GUS histochemical and fluorometric analysis were conducted to investigate the expression of GUS gene in transgenic A.thaliana in response to various stress treatment. 


\subsection{METHODOLOGY}

\subsection{Materials}

P.minor was obtained from in vitro cultures that were maintained on solid Murashige and Skoog medium. The mother plants were originated from Ulu Yam, Selangor, Malaysia. In vitro culture around 7 to 8 weeks has been used in this experiment. Seeds of $A$. thaliana Col-0 were obtained from Plant Biotechnology Laboratory, UKM. A. thaliana Col-0 was grown in a growth chamber maintained at a temperature of $22 \circ \mathrm{C}$ day/ $20 \circ \mathrm{C}$ night and relative humidity of $50-70 \%$. The photoperiod was set at 16 hday/8 h night, with a light intensity of 100-150 umoles $\mathrm{m}^{-2} \mathrm{~s}^{-1}$ using fluorescent bulbs.

\subsection{Cloning and in silico Analysis of PmSS Promoter}

The full-length sequence of PmSS gene information was taken from NCBI (GenBank accession no.KT192706). The PmSS promoter region was isolated using Genome Walker Universal Kit (Clonetech) from genomic DNA of Persicaria minor leaves. Then, PmSS promoter was cloned into a PGEM-T easy vector and subsequently sequenced. Putative cis-acting elements of PmSs promoter was analyzed using PlantCare

(http://bioinformatics.psb.ugent.be/webtools/plantc are/html/)[22] and PLACE database (http://www.dna.affrc.go.jp/PLACE/signalup.html) [23]. The

\subsection{Generation of Promoter Deletion GUS Constructs}

Three promoter deletion were conducted by PCR amplification using three forward primers and a universal reverse primer as listed in Table 1. The full length of PmSS promoter and amplified deletion promoter fragments PmSSDI(-1540/+66), PmSSD2($1078 /+66)$ and PmSSD3 $(-855+66)$ were fused with GUS gene using Gateway Cloning Kit from Invitrogen to assess the promoter activity. The PCR products of PmSS, PmSSD 1, PmSSD2 and PmSSD3 were cloned into the pDONRTM221 using Gateway BP recombination reaction and transformed into E.coli strain Top 10. Then, all the constructs were extracted using GeneJET Plasmid Miniprep from ThermoFisher Scientific and sequenced for verification. Using Gateway LR recombination reaction, all constructs were inserted into a destination vector pBGWFS7.0 which contains GUS gene. These recombinant vectors and a pBGWFS7 .0 vector without promoter (control) were transferred into Agrobacterium tumefaciens strain GV3101 by using the freeze-thaw method.
Table 1 Primer sequences used in promoter deletion

\begin{tabular}{ll}
\hline Primer & Primer sequence (5' -3') \\
\hline PmSSD1_F & 5'- GGG GAC AAG TTT GTA CAA AAA AGC \\
& AGG CTG GGT TCA AAT CTC A -3' \\
\hline PmSSD2_F & $5^{\prime}-$ GGG GAC AAG TTT GTA CAA AAA AGC \\
& $\frac{\text { AGG CTC GCC ACT GTT CGT GTC TC GTG TAT }}{\text { GT -3' }}$ \\
\hline PmSSD3_F & 5'- GGG GAC AAG TTT GTA CAA AAA AGC \\
& AGG CTA CCC AAC CAA AGT TGA CTA -3' \\
\hline PmSS_R & 5'- GGG GAC CAC TTT GTA CAA GAA AGC \\
& TGG GTC CGA CGA TCG AGC GAT GTG GTC \\
\hline
\end{tabular}

2.4 Transformation of $A$. thaliana Expressing GUS Reporter Fusions

The A.tumefaciens carrying PmSS, PmSSD 1, PmSSD2, PmSSD3 and PBGWFS7.0 were transferred into A.thaliana by floral dip method [24]. Transformed A.thaliana were directly screened by spraying with the herbicide Basta $(120 \mu \mathrm{g} / \mathrm{ml})$ on 10th, 12th, 15th and 17th day after germination (DAG). Resistance A.thaliana expected to be transgenic and confirmed by PCR using the same specific primers as listed in Table 1. Segregation test was conducted on T2 seeds to get single copy number line and was kept grow to obtain T3 seeds. Homozygosity test was performed on T3 seeds for each construct to obtain homozygous seeds and used for promoter functional analysis.

\subsection{Hormone and Abiotic Stress Treatment}

Homozygous transgenic A.thaliana were grown on MS medium for functional analysis. 2 weeks old seedlings of transgenic A.thaliana were treated with hormone and abiotic stress treatment. For wound treatment, A.thaliana leaves were crushed several times with laminated forcep which effectively wounded around $40 \%$ of leaf area. Plants were incubated for 1 hour before proceeding with GUS histochemical and fluorometric test. For drought stress treatment, A.thaliana seedlings were put on the surface of dry filter paper and incubated in a growth chamber at $22{ }^{\circ} \mathrm{C}$ for 6 hours [25]. Heat stress treatment was conducted as described by Eun et al. [25] with slight modification. A.thaliana seedlings on MS plate were incubated at $37^{\circ} \mathrm{C}$ for 6 hours in the dark instead of transfer to filter paper saturated with MS medium. ABA and MeJa treatments were conducted as described by Kim et al. [26] with slight modification. A.thaliana seedlings were transferred to filter paper dampened with $100 \mu \mathrm{M} \mathrm{ABA}$ and filter paper dampened with $100 \mu \mathrm{M}$ MeJa instead of filter paper saturated with MS medium and incubated for $24 \mathrm{~h}$ at $22^{\circ} \mathrm{C}$ in the dark. 


\subsection{GUS Histochemical Staining}

Histochemical staining for GUS activity was performed on treated A.thaliana seedlings and at different developmental stages of A.thaliana according to the method reported by Jefferson et al. [27]. Transgenic A.thaliana seedlings were incubated in $1 \mathrm{~mL} X$-Gluc solution for $24 \mathrm{~h}$ at $37^{\circ} \mathrm{C}$. Then, for destaining samples were soaked in $50 \%$ alcohol solution for $24 \mathrm{~h}$ solution.

\subsection{GUS Fluorometric Analysis}

For the fluorometric assay, FluoroAce $\beta$ glucuronidase Reporter Assay (BioRad) was used and conducted according to manufacturer' settings. Transgenic A.thaliana seedlings were homogenized in GUS extraction buffer. Specific volume $(30 \mu \mathrm{g})$ of A.thaliana extract were added to $500 \mu \mathrm{L}$ assay buffer (1.2 mM MUG, $10 \mathrm{mM} \beta$-mercaptoethanol and $1 \mathrm{X}$ reaction buffer). The mixture was vortex and incubated for 30 minutes at $37^{\circ} \mathrm{C}$. I $\mathrm{mL}$ stop buffer was added to the incubated sample. Then, relative fluorescence units (RFU) were measured by VersaFluor Fluorometer 100 (Bio Rad) according to FluoroAce $\beta$-glucuronidase Reporter Assay (Bio-Rad 2000 instruction's manual.

\subsection{RESULTS AND DISCUSSION}

\subsection{Cloning of the PmSS Promoter Region and its Deletion Derivatives}

The full length of PmSS promoter region from $P$. minor was cloned and sequenced in order to identify the putative cis -elements exist in PmSS promoter. The 1758 bp promoter region and 66-bp 5'UTR of PmSS promoter was obtained from the P.minor genomic DNA (GenBank accession no. MH423578). The transcription start site located 75 bp upstream of the ATG translational codon (GenBank accession no.KT192706) was determined by 5'RACE. PmSS putative promoter sequences was evaluated in silico by using PLACE and PlantCare database to identified cis-regulatory elements. The core promoter containing putative CAAT and TATA boxes were detected at $-52 \mathrm{bp}$ and $-18 \mathrm{bp}$, respectively. In contrast, the CAAT and TATA boxes in Elaeis oleifera sesquiterpene synthase promoter were observed at 352 and-25 bp [16]. Numerous potential putative cis elements associated with hormone responsive and environmental stress were discovered in the PmSS promoter region as shown in Table 2.

A few putative cis elements that are involved in $A B A$ responsiveness were detected including $A B R E$ motif which is responsive towards ABA [28-29] and MYCATRD22 motif which is a binding site for MYC protein when induced by ABA [29]. Furthermore, cis elements that responsive toward dehydration also have been found in PmSS promoter including MYCCONSENSUSAT and MYCATERDIwhich are MYC recognition site is found in the promoters of the dehydration-responsive gene rd22 and necessary for expression of erdl in dehydrated Arabidopsis [29], whereas MYB2CONSENSUSAT and MYB1AT were MYB recognition site which is responsive toward dehydration. MYC and MYB transcription factor are synthesized when the accumulation endogenous ABA occured [30]. Other important motifs that were found in PmsS promoter are WUN motif which is cis elements that responsive towards wounding, TC, the cis element that are responsive in defense and stress responsiveness, GTIGMSCAM4 motif which is induced by pathogen and salt [31] and GATABOX, cis elements involved in light regulation. Prior study of sesquiterpene synthase promoter in Artemisia annua also have identified the WUN, HSE, TC, ABRE and GATABOX motifs [17] on the promoter. This indicates, the sesquiterpene synthase expression was regulated by the hormone and the environmental factors.

Several significant cis regulatory elements were selected for promoter deletion study to understand the regulation of PmSS promoter. These including cis regulatory element involved in $A B A$ responsiveness (ABRE) located at -922 bp; cis- regulatory element involved in heat stress responsiveness (HSE) located at -1116 and -1232 bp; cis-acting element involved in wound responsiveness (WUN) located at -1598 bp, and cis - acting element involved in defense and stress responsiveness (TC) located at- 1529,-1333 and -12 bp. Previous studies reported that herbivore attacks in the plants resulted in sesquiterpene emission from the plants to attracts enemies of the herbivore.

In response to herbivore attack to attract natural enemies of the herbivore, sesquiterpene act as indirect defense system in several plants species including Z. mays, Oryza sativa and A.thaliana, [10] [32-33]. Based on, in silico results, several factors that might control the regulation of PmSS gene during plant stress can be identified.

Table 2 Putative cis-regulatory elements identified in the PmSS promoter based on PlantCARE and PLACE database

\begin{tabular}{|l|l|l|l|}
\hline $\begin{array}{l}\text { Regulatory } \\
\text { element }\end{array}$ & Sequence & Location & Function \\
\hline WUN & TCATTACGAA & $1598(-)$ & $\begin{array}{l}\text { involved in } \\
\text { wound } \\
\text { responsiveness }\end{array}$ \\
\hline TC & $\begin{array}{l}\text { ATTTCTCCA, } \\
\text { ATTTTCTTCA }\end{array}$ & $\begin{array}{l}1529(+), \\
1333(-)\end{array}$ & $\begin{array}{l}\text { involved in } \\
\text { defense and } \\
\text { stress } \\
\text { responsiveness }\end{array}$ \\
\hline HSE & AAAAAATTTC & $\begin{array}{l}1116(+), \\
1232(+)\end{array}$ & $\begin{array}{l}\text { involved in } \\
\text { heat stress } \\
\text { responsiveness }\end{array}$ \\
\hline ABRE & AGTACGTGGC & $922(+)$ & $\begin{array}{l}\text { involved in } \\
\text { ABA } \\
\text { responsiveness }\end{array}$ \\
\hline MYBCORE & CNGTTR & $1745(-)$, & \begin{tabular}{l} 
MYB binding \\
\hline
\end{tabular}
\end{tabular}




\begin{tabular}{|c|c|c|c|}
\hline Regulatory & Sequence & Location & Function \\
\hline & & $1738(-)$ & $\begin{array}{l}\text { site. Involved } \\
\text { in drought } \\
\text { tolerance }\end{array}$ \\
\hline $\begin{array}{l}\text { MYB2CON } \\
\text { SENSUSAT }\end{array}$ & YAACKG & $\begin{array}{l}1738(+) \\
29(-)\end{array}$ & $\begin{array}{l}\text { MYB } \\
\text { recogntion } \\
\text { site. Involved } \\
\text { in drought } \\
\text { tolerance }\end{array}$ \\
\hline $\begin{array}{l}\text { GTIGMSC } \\
\text { AM4 }\end{array}$ & GAAAAA & $\begin{array}{l}1560(-), \\
1239(+), \\
481(+)\end{array}$ & $\begin{array}{l}\text { Involved in salt } \\
\text { and pathogen } \\
\text { induction }\end{array}$ \\
\hline GATABOX & GATA & $\begin{array}{l}1518(-), \\
1320 \quad(+), \\
1195(-), \\
881 \quad(-), \\
502(+)\end{array}$ & $\begin{array}{l}\text { Light } \\
\text { responsive } \\
\text { element }\end{array}$ \\
\hline $\begin{array}{l}\text { MYCCONS } \\
\text { ENSUSAT }\end{array}$ & CANNTG & $\begin{array}{l}1472(+), \\
1323(-), \\
895(+), \\
757(-), \\
51(-), \quad 723 \\
(-)\end{array}$ & $\begin{array}{l}\text { MYC } \\
\text { recognition } \\
\text { site. Involved } \\
\text { in cold and } \\
\text { drought } \\
\text { tolerance }\end{array}$ \\
\hline MYBIAT & WAACCA & $1381(+)$ & $\begin{array}{l}\text { MYB } \\
\text { recognition } \\
\text { site. Involved } \\
\text { in drought } \\
\text { tolerance }\end{array}$ \\
\hline $\begin{array}{l}\text { WBOXNTER } \\
\text { F3 }\end{array}$ & TGACY & $840(+)$ & $\begin{array}{l}\text { Involved in } \\
\text { wounding } \\
\text { stress }\end{array}$ \\
\hline $\begin{array}{l}\text { MYCATRD2 } \\
2\end{array}$ & CACATG & $723(-)$ & $\begin{array}{l}\text { MYC binding } \\
\text { site, } A B A \\
\text { responsive } \\
\text { element }\end{array}$ \\
\hline $\begin{array}{l}\text { MYCATERD } \\
1\end{array}$ & CATGTG & $723(+)$ & $\begin{array}{ll}\text { Involved in } \\
\text { drought } \\
\text { tolerance }\end{array}$ \\
\hline
\end{tabular}

${ }^{*}(+)$ : sense strand ; (-):antisense strand

To identify the significant regulatory region of PmSS promoter three series of deletion were generated to obtain three truncated fragments which are PmSSD 1, 1606 -bp fragment without WUN motif, PmSSD2 1144 - bp fragment without WUN, TC and HSE motifs, and PmSSD3 921-bp fragment without WUN, TC, HSE and ABRE motifs. The full length of PmSS promoter and its three 5' deletion fragments were inserted into pBGWFS7.0 vector with GUS reporter gene to analyze the promoter activity. Figure 1 show schematic diagram of the PmSS promoter. Transgenic A.thaliana carrying all constructs were created using floral dip method [25]. The single copy gene was detected by performed segregation test on T2 transgenic lines. The T3 homozygous and single copy transformants were used for promoter functional analysis

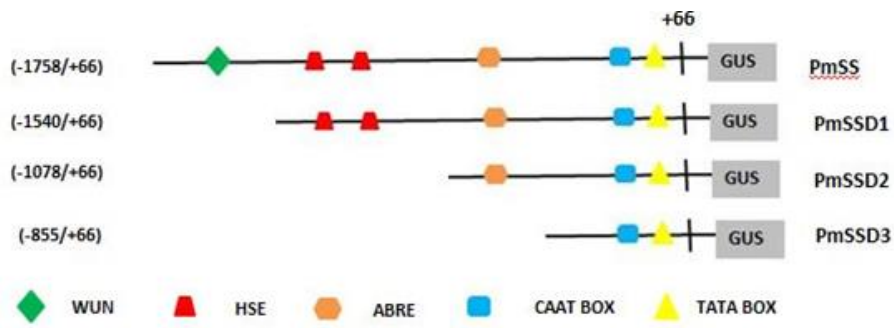

Figure 1 A schematic diagram of PmSS, PmSSD1, PmSSD2, and PmSSD3 promoter fused with GUS reporter gene in the pBGWFS7.0 vector. The putative cis regulatory elements are exhibited by different symbols. The numbers show the nucleotide position of each PmSS promoter fragment

3.2 Developmental-specific Activity of the PmSS Promoter in Transgenic Arabidopsis

In order to evaluate the expression pattern of the PmSS gene at different developmental stages, the GUS expression pattern of transgenic A.thaliana carrying all the promoter constructs were analyzed. Different developmental stages of A.thaliana transformants expressing PmSS, PmSSD 1, PmSSD2, PmSSD3 and control (pBGWFS7.0) plants were subjected to histochemical staining to observed GUS expression pattern. The GUS expression pattern was observed at 3 days after germination (DAG), 7 DAG and 14 DAG seedlings. Figure 2 shows the results of GUS histochemical staining in PmSS, PmSSD I, PmSSD2, PmSSD3 and control plants in different developmental stages. In the PmSS plants, GUS expression was detected only in leaf, hypocotyl and a small area of the root. However, in the 7 DAG and 14 DAG seedlings GUS activity was observed in the entire transgenic Arabidopsis seedlings tissue. Whereas in the PmSSDI plant, GUS expression level was lowest compared to other constructs. GUS expression was detected only at the root tip in 3 DAG seedlings. In the 7 DAG seedlings, GUS expression was located at the tip of leaf apex and root tip. Strong GUS expression was observed at leaf vein and lower GUS expression at the root tip in the 14 DAG seedlings compared to 3 DAG and 7 DAG seedlings. This result indicate that PmSS and PmSSDI promoter activity regulated developmental specific gene expression. However, strong GUS expression was observed in the entire PmSSD2 seedlings tissue of the 3 DAG, 7 DAG and 14 DAG seedlings. GUS expression was observed only at the stem of PmSSD3 seedlings of the 3 DAG, 7 DAG and 14 DAG. The GUS expression of PmSSD2 and PmSSD3 transgenic Arabidopsis seedlings were consistent from 3 DAG till 14 DAG. This revealed that PmSSD2 and PmSSD3 promoter construct do not direct plant developmental specific gene expression. Whereas no GUS expression was detected in control plants, suggested there is no endogenous GUS activity in A.thaliana. Based on the developmentalspecific activity of all the constructs, revealed that 
unknown regulatory elements that control plant developmental specific gene expression might exist between - 1758 to -1078 bp on PmSS promoter.

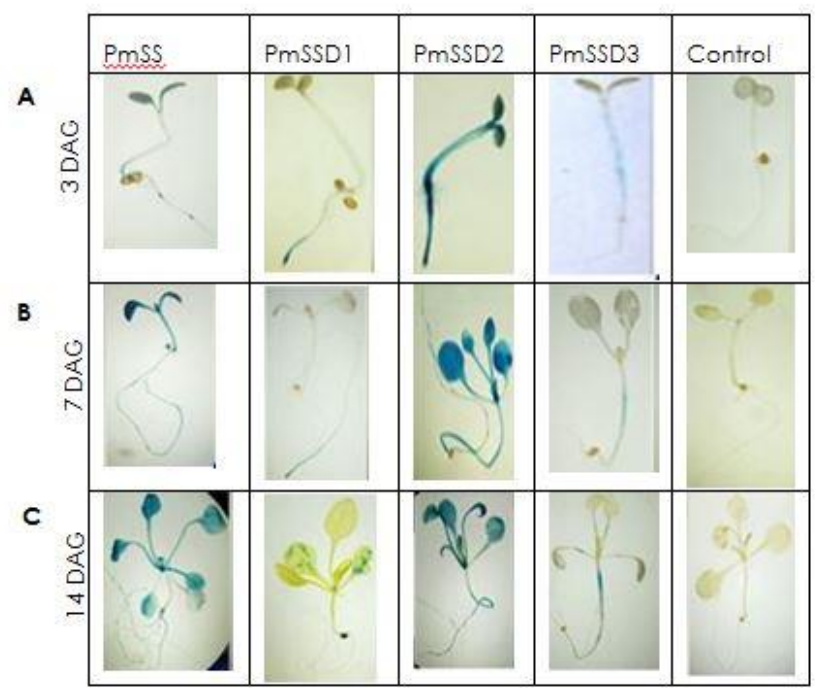

Figure 2 GUS histochemical staining and qualitative GUS expression in transgenic PmSS, PmSSD1, PmSSD2, PmSSD3 promoter and control (pBGWFS7.0) plants at (A) 3 DAG seedlings, (B) 7 DAG seedlings and (C) 3 DAG seedlings

The fluometric analysis reveals that the PmSSD2 plants GUS activity was the highest, whereas GUS activity in the PmSS, PmSSDI and PmSSD3 were 1.1, 41.6 and 14 fold lower compared to PmSSD2 plants (Figure 2). These data are consistent with GUS histochemical staining results. Deletion of a PmSS promoter region from -1758 to -1540 bp induced a sharp decrease in GUS activity by 37 fold(PmSSD 1). However, further deletion from -1758 to $-1078 \mathrm{bp}$ in PmSSD2 construct strongly induced GUS activity by 41 fold. This result shows that the promoter region from1758 to-1078 was critical in maintaining maximal promoter activity and have vital regulatory elements. Besides that, it also illustrates that there might be enhancer at region -1758 to -1540 that activated PmSS promoter activity and unknown regulatory cis element that act as a repressor at -1540 to -1078 region. Prior studies confirmed that GUS expression of the of CRTISO promoter, a Citrus unshiu carotenoid isomerase only observed in shortest construct compared to the long promoter constructs when treated with ethylene, indicated that putative repressor element(s) might present in the promoter region between -2325 and -861 bp [25]. Deletion of $218 \mathrm{bp}$ promoter fragment might activate specific repressor that inhibits GUS gene expression at PMSSD 1 plants. The loss of a region from-1758 to -855 in PmSSD3 constructs cause the GUS activity only expressed at the stem of PmSSD3 plants. These data indicate that, PmSSD3 constructs is a tissue-specific promoter. Combination of promoter cis- regulatory elements (CREs) aid the binding of several transcription factors, resulted in the change of the gene expression pattern (34].

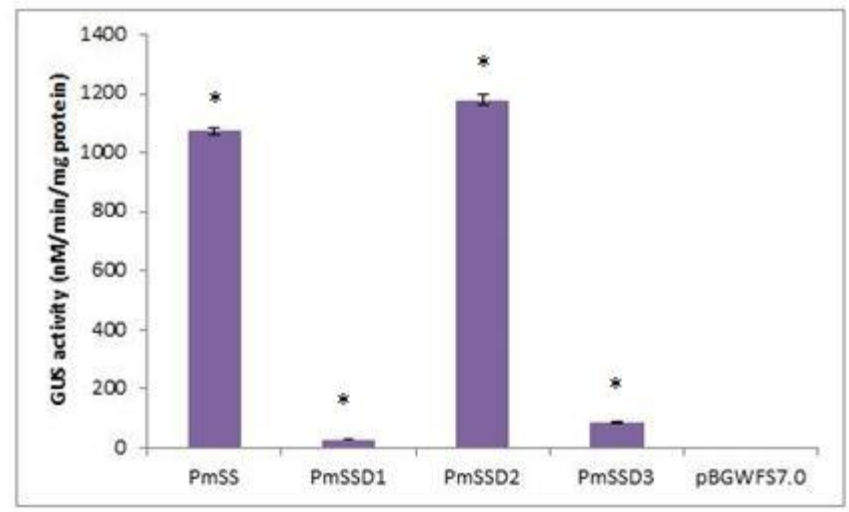

Figure 2 Activity of GUS in 14 DAG PmSS (-1758/66), PmSSD 1 $(-1540 /+66), \operatorname{PmSSD} 2(-1078 /+66)$, and PmSSD3 $(-855 /+66)$ transgenic Arabidopsis seedlings analyzed fluorometrically. Significant differences were determined by Fisher's least significant difference test $(P<0.01)$

\subsection{Functional Analysis of cis-regulatory Elements in the PmSS Promoter}

Several cis regulatory elements were selected for promoter deletion study to examine the regulation and vital regulatory region pf PmSS promoter including WUN, TC, HSE, and ABRE motifs. To evaluate whether these selected cis-elements were functional, 2 - weeks old seedlings of transgenic Arabidopsis with all constructs were treated with hormone and environmental stress. Histochemical GUS staining and fluorometric test of GUS expression were conducted to these treated transgenic A.thaliana. GUS histochemical staining result has shown that there were no differences of GUS expression pattern between treated and non-treated transgenic PmSS promoter-GUS line. However, there was a difference in concentration of GUS expression in fluorometric analysis results between treated and non-treated transgenic A.thaliana.

Based on GUS fluorometric analysis result have shown GUS activity was higher in transgenic A.thaliana PmSS promoter-GUS line that received wounding, heat and $A B A$ treatment compared to non-treated transgenic A.thaliana. The PmSS, PmSSD 1, PmSSD2 and PmSSD3 plants treated with wounding treatment showed a 1.3-, 5.3-, 1.1 and 1.5fold increase in GUS activity, respectively (Figure 3). In A.annua, similar to PmSS promoter, the four sesquiterpene synthase promoters which are $\beta$ caryophyllene (CPS), $\beta$-farnesene (FS), epi-cedrol (ECS) and amorpha-4,11-diene synthase (ADS) were induced by wounding treatment[17]. These findings conclude that, PmSS genes might be induced in response to herbivory attacks as a defense mechanism. 
Heat stress treatment induced 1.5-, 2.8-, 1.9- and 1.6fold increases in GUS activity in the PmSS, PmSSD 1, PmSSD2 and PmSSD3 respectively (Figure 3). The PmSS, PmSSD1, PmSSD2 and PmSSD3 plants treated with ABA increased GUS activity 2.9-, 2-, 1.8- and 1.2 fold respectively (Figure 3 ) Deletion of WUN, HSE and ABRE motifs has no significant impact on PmSS promoter activity. These results suggest that activity of PmSS promoter does not depend on WUN, HSE and $A B R E$ motifs under wounding, heat and $A B A$ treatment. Furthermore, WBOXNTERF3 motif which is involved in wounding stress and MYCATRD22 motif which is $A B A$ responsive element [35] exists in all promoter constructs.

Drought treatment induced GUS activity in all construct except PmSSD3 construct promoter. The PmSS, PmSSD 1 and PmSSD2 plants were responsive to the drought treatment, resulting in 1.5-, 4.5- and 2.6fold increase of GUS activity, respectively. However, the GUS activity was decrease by 2.3 fold in PmSSD3 plants. Deletion of ABRE motif at $-922 \mathrm{bp}$ in PmSSD3 construct decreased promoter activity after received drought treatment. The previous study has found that, drought stress increased the production of $A B A$ resulted in activation of MYC and MYB transcription factors, thereby induced the expression of the gene. [30]. The absence of ABRE motifs on PmSSD3 promoters might not activate the MYC and MYB transcription factors which explain why the activity of PmSSD3 promoter not induced by drought stress treatment. This deduced ABRE play a critical role in PmSS promoter regulation under drought stress.

MeJa treatment induced GUS activity in PmSS and PmSSD2 constructs. GUS activity in PmSS and PmSSD2 construct increased by 3 and 1.8 fold after treated with MeJa. The previous study has reported that the expression of PmSS gene was responsive towards the elicitation of jasmonic acid in all organs of the P. minor. Furthermore, application of Jasmonic acid (JA) towards in vitro culture of P.minor significantly increased the production of sesquiterpene [19] The transcript level of four sesquiterpene synthase promoter in A.annua increased after the Meja treatment [17]. However GUS activity was decreased 4 - and 2.7- fold in PmSSD1 and PmSSD3 constructs. The deletion of promoter region from $-1758 \mathrm{bp}$ to $-1540 \mathrm{bp}$ induced a sharp decrease in GUS activity which is 3.9 fold when treated with MeJa. These results suggest there might have unknown regulatory elements presents in the PmSS promoter region from -1758 to -1540 bp that responsive towards MeJa. However, there is no GUS activity was detected in treated control plants, indicated the absence of endogenous GUS activity.

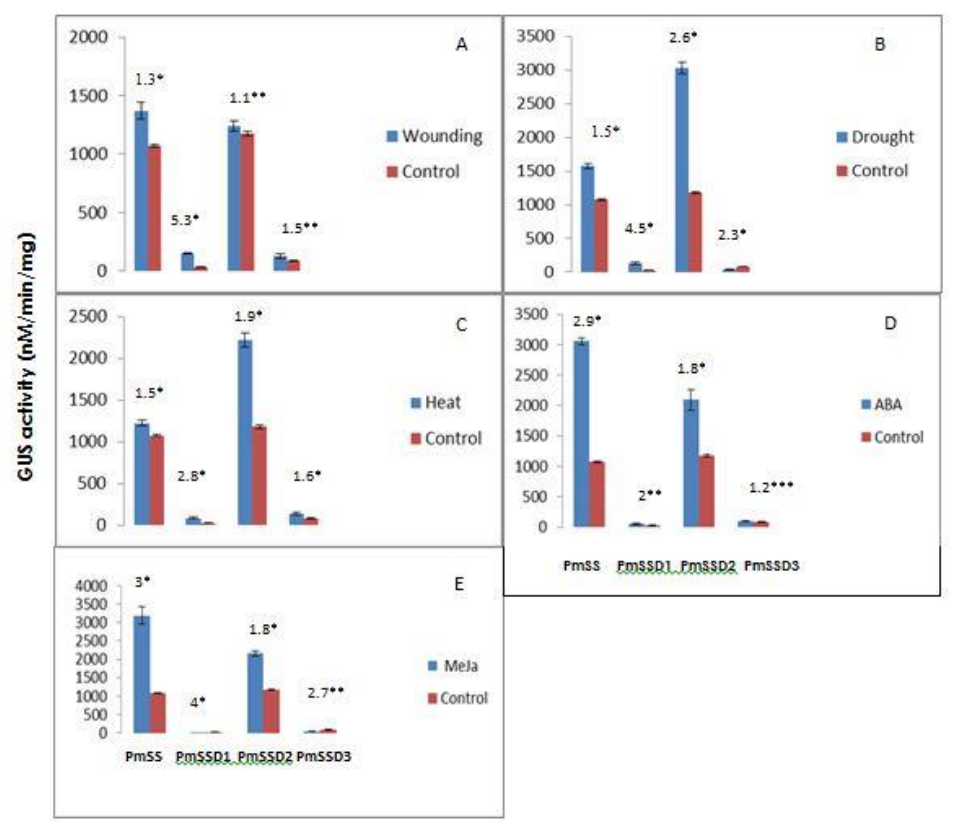

Figure 3 Activity of GUS in 14 DAG PmSS (-1758/+66), PmSSD 1 (-1540/+130), PmSSD2 (-1078/66) and PmSSD3 ($855 /+66)$ transgenic Arabidopsis seedlings treated with with wounding(A), drought(B), heat stress (C), $100 \mu \mathrm{M}$ Abscisic acid (ABA)(D) and $100 \mu \mathrm{M}$ methyl jasmonate (MeJA) (E), The numbers over the bars represent GUS activity fold increase in response to the stress treatment versus the control. Significant differences between the treatment and control were determine by the two-tailed unpaired t-test ( ${ }^{*} \mathrm{P}<0.01$, ${ }^{* *} \mathrm{P}<0.05, \mathrm{P}>0.05$ )

\subsection{CONCLUSION}

Pmss promoter possessed several cis-regulatory elements that are responsive to hormone and environmental stress. The functional analysis of the Pmss gene has proven that PmSs promoter directs developmentally specific gene expression. Pmss promoter was induced by wounding, drought, heat, $A B A$ and Me Ja treatment. Deletion of WUN, HSE and ABRE did not affect GUS activity in PmSSD 1, PmSSD2 and PmSSD3 plants when treated with wounding, heat stress and ABA treatment. These indicate, WUN, HSE and ABRE motif might not have functional activity in PmSS promoter. Wounding, heat stress and ABA treatment did not affect GUS activity in three truncated PmSS-GUS constructs, indicate WUN. HSE and $A B R E$ motif might not have functional activity in PmSS promoter. The highest GUS activity was found in PmSSD2 plants $(-1078 /+66)$, therefore the region from -1078 to $-855 \mathrm{bp}$ presents in Pmss promoter was important for maximal activity of the promoter. In contrast, GUS activity in PmSSD 1 plants $(-1540 /+66)$ was the lowest, demonstrated there are unknown cis element that act as repressor between region -1540 to-1078 bp. The deletion of -1540 to -1078 bp region in PmSS promoter highly increased the promoter 
activity. PmSSD3 plants were expressed in tissue specific manner, GUS activity only observed at the plant's stem. PmSSD3 construct might have an unknown cis elements that control specific tissue gene expression in PmSS promoter located at -855 to +1 bp. Further analysis need to be performed to identify unknown cis-regulatory elements that control the regulation of PmSS promoter in the truncated promoter. In conclusion, this research has provided a new insight to understand the critical region in PmSS promoter and in plant metabolism.

\section{Acknowledgements}

The authors are grateful to Universiti Kebangsaan Malaysia (UKM) and Institute of Systems Biology (INBIOSIS) for providing the funding and facilities for conducting this research.

\section{References}

[1] Dudareva, N., Negre, F., Nagegowda, D. A. and Orlova, I. 2007. Plant Volatiles: Recent Advances and Future Perspectives. Critical Reviews in Plant Sciences. 25(5): 417440. DOI: https://doi.org/10.1080/07352680600899973.

[2] Nagegowda, D. A. 2010. Plant Volatile Terpenoid Metabolism Biosynthetic Genes. Transcriptional Regulation and Subcellular Compartmentation. 584: 2965-2973.

[3] Buckle, J. 2015. Basic Plant Taxonomy, Basic Essential Oil Chemistry, Extraction, Biosynthesis, and Analysis. Clinical Aromatherapy. 37-72. DOI: https://doi.org/10.1016/B978-0-7020-5440-2.00003-6.

[4] Mazid, M., Khan, T. A. and Mohammad, F. 2011. Role of Secondary Metabolites in Defense Mechanisms of Plants. Biology and Medicine. 3(2): 232-249.

[5] Awouafack, M. D., Tane, P., Kuete, V. and Eloff, J. N. 2013. Sesquiterpenes from the Medicinal Plants of Africa. Medicinal Plant Research in Africa: Pharmacology and Chemistry. 33-103.

[6] Göpfert, J. C., Macnevin, G., Ro, D. and Spring, O. 2009. Identification, Functional Characterization and Developmental Regulation of Sesquiterpene Synthases from Sunflower Capitate Glandular Trichomes. BMC Plant Biology. 18: 1-18.

[7] Lockwood, G. B. 2001. Techniques for Gas Chromatography of Volatile Terpenoids from a Range of Matrices. Journal of Chromatography A. 936: 23-31.

[8] Chen, F., Tholl, D., Auria, J. C. D., Farooq, A., Pichersky, E. and Gershenzon, J. 2003. Biosynthesis and Emission of Terpenoid Volatiles from Arabidopsis Flowers. The Plant Cell. 15: 481-494. DOI: https://doi.org/10.1105/tpc.007989.

[9] Gouinguene, S., Degen, T. and Turlings, T. C. J. 2001. Variability in Herbivore-induced Odour Emissions qmong Maize Cultivars and Their Wild Ancestors (Teosinte) Variability in Herbivore-induced Odour Emissions among Maize Cultivars and Their Wild Ancestors (Teosinte). Chemoecology. 11(1): 9-16. DOI: https://doi.org/10.1007/PL00001832.

[10] Kollner, T. G., Held, M., Lenk, C., Hiltpold, I., Turlings, T. C. J., Gershenzon, J. and Degenhardt, J. 2008. A Maize (E)- $\beta$ Caryophyllene Synthase Implicated in Indirect Defense Responses against Herbivores is Not Expressed in Most American Maize Varieties. The Plant Cell Online. 20(2): 482-494.

DOI: https://doi.org/10.1105/tpc.107.051672.
[11] Huang, M., Sanchez-Moreiras, A.M., Abel, C., Sohrabi, R., Lee, S., Gershenzon, J. and Tholl, D. 2012. The major volatile organic compound emitted from Arabidopsis thaliana flowers, the sesquiterpene (E)--caryophyllene, is a defense against a bacterial pathogen. New Phytologist 193(4): 997-1008. DOI: https://doi.org/10.1111/j.1469-8137.2011.04001.

[12] Picaud, S., Olsson, M.E., Brodelius, M. and Brodelius, P.E. 2006. Cloning, Expression, Purification and Characterization of Recombinant (+) -Germacrene D Synthase from Zingiber Officinale. Archives of Biochemistry and Biophysic. 452: 17-28. DOI: https://doi.org/10.1016/j.abb.2006.06.007.

[13] Lange, B. M., Rujan, T., Martin, W. and Croteau, R. 2000. Isoprenoid Biosynthesis: The Evolution of Two Ancient and Distinct Pathways across Genomes. Proceedings of the National Academy of Sciences. 97(24): 13172-13177. DOI: https://doi.org/10.1073/pnas.240454797

[14] Hernandez-Garcia, C. M. and Finer, J. J. 2014. Identification and Validation of Promoters and cis-acting Regulatory Elements. Plant Science. 217-218: 109-119. DOI: https://doi.org/10.1016/j.plantsci.2013.12.007.

[15] Zou, C., Sun, K., Mackaluso, J. D., Seddon, A. E., Jin, R. \& Thomashow, M. F. 2011. Cis -regulatory Code of StressResponsive Transcription in Arabidopsis Thaliana. Proceedings of the National Academy of Sciences of the United States of America 108. (2011): 14992-14997). DOI: https://doi.org/10.1073/pnas.1 103202108.

[16] Ismail, I., Abdul Rahman, N., Fei, C. K., Zainal, Z., Sidik, N. M., and Che Mohd Zain, C. R. 2009. Functional Analysis of the Elaeis Oleifera Sesquiterpene Synthase Promoter Reveal Non-Specific Tissue Expression and Activation under Stress Condition. American Journal of Plant Physiology. 4(1): 24-37. DOI: https://doi.org/10.3923/ajpp.2009.24.37.

[17] Wang, H., Han, J., Kanagarajan, S., Lundgren, A., and Brodelius, P. E. 2013. Studies on the Expression of Sesquiterpene Synthases using Promoter- $\beta$-glucuronidase Fusions in Transgenic Artemisia annua L. PLOS One. 8(11): e80643. DOI: https://doi.org/10.1371/journal.pone.0080643.

[18] Baharum, S. N., Bunawan, H., Ghani, M. A., Wan Aida Wan Mustapha and Noor, N. M. 2010. Analysis of the Chemical Composition of the Essential Oil of Polygonum minus Huds. Using Two-dimensional Gas Chromatography-time-of-flight Mass Spectrometry (GC-TOF MS). Molecules. 15(10): 70067015. DOI: https://doi.org/10.3390/molecules15107006.

[19] Gor, M. C., Ismail, I., Mustapha, W. A. W., Zainal, Z., Noor, N. M., Othman, R. and Hussein, Z. A. M. 2011 . Identification of cDNAs for Jasmonic Acid-responsive Genes in Polygonum Minus Roots by Suppression Subtractive Hybridization. Acta Physiologiae Plantarum. 33(2): 283-294. DOI: https://doi.org/10.1007/s1 1738-010-0546-2.

[20] Christapher, P. V., Parasuraman, S., Christina, J. M. A., Asmawi, M. Z. and Vikneswaran, M. 2014. Review on Polygonum minus. Huds, a Commonly used Food Additive in Southeast Asia. Pharmacognosy Research. 7(1): 1-6. DOI: https://doi.org/10.4103/0974-8490.147125.

[21] Kiat, C. J., Ashraf, M. F., Naeem-Ul-Hassan, M., Che Mohd Zain, C. R., Zainal, Z. and Ismail, I. 2016. Molecular Cloning, Characterization and Expression Pattern Analysis of a Jasmonic Acid Responsive Sesquiterpene Synthase Gene from Persicaria minor. Plant OMICS. 9(5): 360-368. DOI: https://doi.org/10.21475/poj.09.05.16.pne271.

[22] Lescot, M., Dehais, P., Thijs, G., Marchal, K., Moreau, Y., Van de Peer, Y., Rouze, P and Rombauts, S. 2002. PlantCARE, Adatabase of Plant cis-acting Regulatory Elements and a Portal to Tools for in Silico Analysis of Promoter Sequences. Nucleic Acids Research. 30: 325-327. DOI: https://doi.org/10.1093/nar/30.1.325. 
[23] Higo, K., Ugawa, Y., Iwamoto, M. and Korenaga, T. 1999. Plant cis Acting Regulatory DNA Elements (PLACE) Database. Nucleic Acid Research. 27: 297-300. DOI: https://doi.org/10.1093/nar/27.1.297.

[24] Clough, S. J and Bent, A. F. 1998. Floral Dip: A Simplified Method for Agrobacterium-mediated Transformation of Arabidopsis thaliana. Plant Journal. 16: 735-743. DOI: https://doi.org/10.1046/j.1365-313x.1998.00343.x.

[25] Eun, C. H., Kim, S. U. and Kim, I. J. 2015. The Promoter from the Citrus unshiu Carotenoid Isomerase Gene Directs Differential GUS Expression in Transgenic Arabidopsis. Molecular Breeding. 35(5). DOI: https://doi.org/10.1007/s1 1032-015-0310-9.

[26] Kim, I. J., Lee, J., Han, J. A. and Kim, C. S and Hur, Y. 2011. Citrus Lea Promoter Confers Fruit-preferential and Stressinducible Gene Expression in Arabidopsis. Canadian Journal of Plant Science. 91: 459-466. DOI: https://doi.org/10.4141/cjps10137.

[27] Jefferson, R. A. 1987. Assaying Chimeric Genes in Plants: the GUS Gene Fusion System. Plant Molecular Biology. 5: 387-405.

[28] Simpson, S. D., Nakashima, K., Narusaka, Y., Seki, M., Shinozaki, K and Yamaguchi-Shinozaki, K. 2003. Two Different Novel cis Acting Elements of erdl, a clpA Homologous Arabidopsis Gene Function in Induction by Dehydration Stress and Dark Induced Senescence. Plant Jounal. 33:259-270 DOI: https://doi.org/10.1046/j.1365-313X.2003.01624.x.

[29] Abe, H., Yamaguchi-Shinozaki, K., Urao, T., Iwasaki, T., Hosokawa, D and Shinozaki, K. 1997.Role of Arabidopsis MYC and MYB Homologs in Drought- and Abscisic Acidregulated Gene Expression. Plant Cell. 9: 1859-1868. https://doi.org/10.1105/tpc.9.10.1859.

[30] Shinozaki, K., \& Yamaguchi-Shinozaki, K. 2007. Gene Networks Involved in Drought Stress Response and Tolerance. Journal of Experimental Botany. 58(2): 221-227.
DOI: https://doi.org/10.1093/jxb/erl164.

[31] Park, H. C., Kim, M. L., Kang, Y. H., Jeon, J. M., Yoo, J. H., Kim, M. C., Park, C. Y., Jeong, J. C., Moon, B. C., Lee, J. H., Yoon, H. W., Lee, S.-H., Chung, W. S., Lim, C. O., Lee, S. Y., Hong, J. C. and Cho, M. J. 2004. Pathogen- and $\mathrm{NaCl}-$ Induced Expression of the SCaM-4 Promoter Is Mediated in Part by a GT-1 Box that Interacts with a GT-1-Like Transcription Factor. Plant Physiology. 135(4): 2150 LP-2161.

[32] Hoballah, M. E., Degen, T., Bergvinson, D., Savidan, A., Tamo, C. and Turlings, T. C. J. 2004. Occurrence and Direct Control Potential of Parasitoids and Predators of the Fall Armyworm (Lepidoptera: Noctuidae) on Maize in the Subtropical. Agricultural and Forest Entomology. 6(1): 8388.

DOI: https://doi.org/10.1111/j.1461-9555.2004.00207.x.

[33] Schnee, C., Kollner, T. G., Held, M., Turlings, T. C. J. Gershenzon, J. and Degenhardt, J. 2006. The Products of a Single Maize Sesquiterpene Synthase form a Volatile Defense Signal that Attracts Natural Enemies of Maize Herbivores. Proceedings of the National Academy of Sciences. Neuchatel, Switzerland. 14 September 2005. 103(4): 1129-1134.

DOI: https://doi.org/10.1073/pnas.0508027103.

[34] Deb, A. and Kundu, S. 2015. Deciphering Cis-Regulatory Element Mediated Combinatorial Regulation in Rice under Blast Infected Condition. PLOS ONE. 10(9). DOI: https://doi.org/10.1371/journal.pone.0137295.

[35] Nishiuchi, T., Shinshi, Hand Suzuki, K. 2004. Rapid and Transient Activation of Transcription of the ERF3 Gene by Wounding in Tobacco Leaves: Possible Involvement of NtWRKYs and Autorepression. Journal of Biological Chemistry. 279: 55355-55361.

DOI: https://doi.org/10.1074/jbc.M409674200. 